\title{
Polystyrene microplastics do not affect juvenile brown trout (Salmo trutta f. fario) or modulate effects of the pesticide methiocarb
}

\author{
Hannah Schmieg ${ }^{1 *}$, Sven Huppertsberg ${ }^{2}$, Thomas P. Knepper ${ }^{2}$, Stefanie Krais ${ }^{1}$, Katharina Reitter ${ }^{1}$, \\ Felizitas Rezbach', Aki S. Ruhl ${ }^{3,4}$, Heinz-R. Köhler ${ }^{1}$ and Rita Triebskorn ${ }^{1,5}$
}

\begin{abstract}
Background: There has been a rising interest within the scientific community and the public about the environmental risk related to the abundance of microplastics in aquatic environments. Up to now, however, scientific knowledge in this context has been scarce and insufficient for a reliable risk assessment. To remedy this scarcity of data, we investigated possible adverse effects of polystyrene particles $\left(10^{4}\right.$ particles $/ L$ ) and the pesticide methiocarb $(1 \mathrm{mg} / \mathrm{L})$ in juvenile brown trout (Salmo trutta $\mathrm{f}$. fario) both by themselves as well as in combination after a $96 \mathrm{~h}$ laboratory exposure. PS beads (density $1.05 \mathrm{~g} / \mathrm{mL}$ ) were cryogenically milled and fractionated resulting in irregular-shaped particles $(<50 \mu \mathrm{m})$. Besides body weight of the animals, biomarkers for proteotoxicity (stress protein family Hsp70), oxidative stress (superoxide dismutase, lipid peroxidation), and neurotoxicity (acetylcholinesterase, carboxylesterases) were analyzed. As an indicator of overall health, histopathological effects were studied in liver and gills of exposed fish.

Results: Polystyrene particles by themselves did not influence any of the investigated biomarkers. In contrast, the exposure to methiocarb led to a significant reduction of the activity of acetylcholinesterase and the two carboxylesterases. Moreover, the tissue integrity of liver and gills was impaired by the pesticide. Body weight, the oxidative stress and the stress protein levels were not influenced by methiocarb. Effects caused by co-exposure of polystyrene microplastics and methiocarb were the same as those caused by methiocarb alone.

Conclusions: Overall, methiocarb led to negative effects in juvenile brown trout. In contrast, polystyrene microplastics in the tested concentration did not affect the health of juvenile brown trout and did not modulate the toxicity of methiocarb in this fish species.
\end{abstract}

Keywords: Microplastics, Pesticide, Methiocarb, Brown trout, Oxidative stress, Acetylcholinesterase, Histopathology

\section{Background}

Public and scientific awareness for the problem of environmental pollution with microplastics (MP) has increased considerably over the last years. MP can be found ubiquitously in marine and freshwater ecosystems and even in remote regions $[8,15,33]$. While most research focuses on the abundance and possible effects

\footnotetext{
*Correspondence: hannah.schmieg@uni-tuebingen.de

1 Animal Physiological Ecology, University of Tübingen, Auf der

Morgenstelle 5, 72076 Tübingen, Germany

Full list of author information is available at the end of the article
}

of MP in marine environments, the number of studies in freshwater ecosystems is also rapidly increasing [33]. Nevertheless, many gaps in knowledge about abundance, toxicity, and hazards of MP in freshwater systems still exist.

Possible effects of MP can be related to mechanical injuries caused by the particles (e.g. [14, 37, 44, 57, 78]). Of particular interest are very small particles (mainly nanoplastics) for which uptake in cells were shown (e.g. [14, $49,77])$. In addition to this physical damage, MP can also potentially affect organisms due to the leakage of hazardous substances like residual monomers, polymerization 
solvents, or additives $[42,68]$. A third process that should be considered in this context is that MP might ad/absorb hydrophobic organic pollutants like PAHs, PCBs, or pesticides (reviewed by [79]) and transport them into organisms. Sorption of hydrophobic organic pollutants to MP is especially important for freshwater, since the concentrations of these pollutants are generally higher than in marine ecosystems [15]. The sorption of organic pollutants to MP may alter the bioavailability of the pollutants (e.g. [31, 38, 53, 54, 62, 70]). Furthermore, Batel et al. [6] showed the possibility of the transfer of organic pollutants adsorbed to MP along an artificial food chain. The biological relevance of MP as vectors for chemicals is still under debate. Several studies suggest the effect of MP to be negligible compared to other exposure pathways and the concentration of organic compounds in most MP to be in equilibrium with the surrounding media (e.g. $[5,7$, 40]). To assess the risk of MP alone and in combination with organic pollutants, more studies under controlled lab conditions are required.

Residues of pesticides are regularly found in freshwater ecosystems (e.g. [10, 39, 71]). Methiocarb (or synonym mercaptodimethur) is a carbamate pesticide, which is used as a molluscicide, herbicide, insecticide, acaricide, and as a repellent in seed treatment [23, 82, 43]. In the US, products containing methiocarb are registered by the EPA for restricted usage [20]. In September 2019, the European Commission did not renew the approval of methiocarb as an active substance [26]. Prior to this decision, products containing methiocarb were generally approved for usage in the EU, although the application as a molluscicide was already prohibited since 2014 [23, 25]. Methiocarb is on the first surface water Watch List under the Water Framework Directive of the European Union and is recommended for the second Watch List [24, 43]. The average surface water concentration of methiocarb in the EU-wide monitoring campaign was between 6 and $40 \mathrm{ng} / \mathrm{L}$, and the maximal concentration $109 \mathrm{ng} / \mathrm{L}$ [43].

The purpose of the present study was to investigate whether polystyrene (PS) MP alone and in co-exposure with methiocarb affect juvenile brown trout (Salmo trutta f. fario). To determine the amount of methiocarb sorbed on PS particles, a separate sorption study would be necessary. Sorption of chemical contaminants to MP involves various mechanisms and depends on physicochemical properties of the sorbate, the sorbent, as well as the medium characteristics [73]. The animals were exposed to either PS-MP alone $\left(10^{4}\right.$ particles/L), to methiocarb alone $(1 \mathrm{mg} / \mathrm{L})$, or co-exposed to both $\left(10^{4}\right.$ particles/L and $1 \mathrm{mg} / \mathrm{L}$ methiocarb) for $96 \mathrm{~h}$. The chosen methiocarb concentration was relatively high to ensure that the effects of methiocarb and hence also a possible modulation could be observed in the experiment. Besides apical endpoints (mortality and body weight), biomarkers for oxidative stress [activity of superoxide dismutase (SOD) and formation of lipid peroxidation (LPO)], proteotoxicity (stress protein family Hsp70) as well as neurotoxicity [acetylcholinesterase (AChE) activity and two protective carboxylesterases $(\mathrm{CbE})]$ were examined. Furthermore, the histopathological status of gills and liver was analyzed. Our purpose was to investigate possible mechanistic effects in juvenile brown trout of PS-MP or methiocarb alone at sub-lethal level and whether PS-MP modulates the toxicity of methiocarb at the tested concentrations.

\section{Materials and methods \\ Test organism}

In the present study, approximately 11-month-old juvenile brown trout were used. Prior to the experiment, trout were acclimated in a $250-\mathrm{L}$ tank to lab conditions (aerated filtered, tap water-iron filter, particle filter, activated charcoal filter) for almost 3 months. Trout originated from a commercial fish breeder (Forellenzucht Lohmühle, D-72275 Alpirsbach-Ehlenbogen, Germany). In regular controls, the breeding establishment is categorized as category I, disease-free (EU [22]).

\section{Test substances}

PS-MP suspensions with a defined number of particles were produced according to the method of Eitzen et al. [17]. The polystyrene particles were analysed by different techniques (Raman and FTIR spectroscopy and TED-GC-MS) in scope of the joint project MiWa (for FTIR spectrum, see Additional file 1: Figure S1). In brief, transparent polystyrene pellets (Polystyrol 158K, BASF, Germany) with a density of $1.05 \mathrm{~g} / \mathrm{mL}$ were cryogenically milled (CryoMill, Retsch, Germany) resulting in irregularly shaped PS-MP particles (Fig. 1). The number of PS particles in the pure suspension was determined with a particle counter (SVSS, PAMAS, Germany) by light extinction in a laser-diode sensor (type HCB-LD-50/50). The particle size distribution is provided in Table 1, a figure in Additional file 1: Figure S2. Subsequently, the particles were fractionated by a micro-sieve (polyamide monofilament) to $<50 \mu \mathrm{m}$, and the permeate was used as stock suspension. Particles below $1 \mu \mathrm{m}$ (e.g. ca. $500 \mathrm{~nm}$ ) were only rarely found in SEM in samples after cryogenic milling much more excessive than applied for the particles used in this study (compare [17]).

Methiocarb was purchased from Sigma-Aldrich (product line: PESTANAL ${ }^{\circledR}$; CAS number: 2032-657; purity 99.8\%; more details in Additional file 1). The octanol/water partition coefficient of methiocarb is log Pow 3.08 [34]. The predicted solubility in water $\left(20^{\circ} \mathrm{C}\right)$ is between 14.23 and $119.63 \mathrm{mg} / \mathrm{L}$ [19]. Nevertheless, 


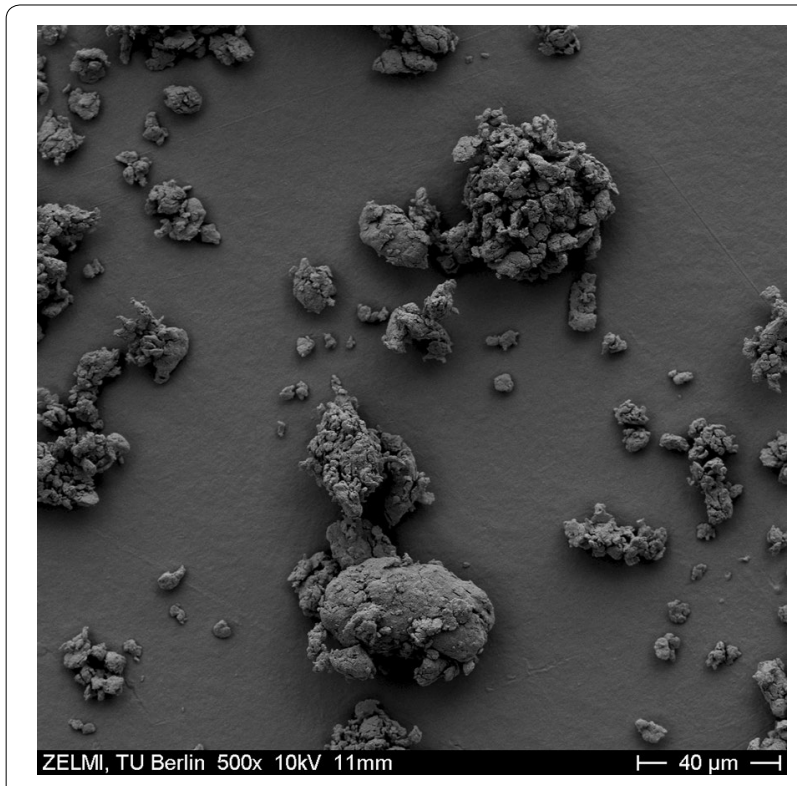

Fig. 1 Electron micrograph of the cryo-milled gold sputtered PS particles (Scanning electron microscope (SEM) Zeiss DSM 982 GEMINI; secondary electron detector)

Table 1 Size ranges (in $\mu \mathrm{m}$ ) and counted particle numbers (per $\mathrm{mL}$ ) of polystyrene particles in the stock suspension

\begin{tabular}{llcc}
\hline Size range $(\boldsymbol{\mu m})$ & $\begin{array}{l}\text { Particle } \\
\text { number }(\mathbf{1} / \\
\mathrm{mL})\end{array}$ & Size range $(\boldsymbol{\mu m})$ & $\begin{array}{l}\text { Particle } \\
\text { number }(\mathbf{1} / \\
\mathrm{mL})\end{array}$ \\
\hline $2-3$ & 9067 & $30-35$ & 643 \\
$3-4$ & 6488 & $35-40$ & 473 \\
$4-5$ & 8872 & $40-50$ & 511 \\
$5-6$ & 4832 & $50-60$ & 220 \\
$6-7$ & 3770 & $60-70$ & 89 \\
$7-8$ & 3484 & $70-80$ & 43 \\
$8-9$ & 3076 & $80-90$ & 18 \\
$9-10$ & 2412 & $90-100$ & 6 \\
$10-12$ & 3259 & $100-150$ & 5 \\
$12-14$ & 2330 & $150-200$ & 0 \\
$14-16$ & 1628 & $200-250$ & 0 \\
$16-18$ & 1195 & $250-300$ & 0 \\
$18-20$ & 1081 & $300-350$ & 0 \\
$20-25$ & 1698 & $350-400$ & 0 \\
$25-30$ & 1041 & & \\
\hline
\end{tabular}

it was not possible to dissolve $15 \mathrm{mg} / \mathrm{L}$ methiocarb without a solvent. Therefore, $0.01 \%$ dimethyl sulfoxide (DMSO) was used to dissolve methiocarb in water.

\section{Exposure of juvenile brown trout}

Fish were exposed in a static three-block design for $96 \mathrm{~h}$ (18.10.2017-23.10.2017). Each of the three blocks consisted of five tanks with the different treatment groups: a negative control group (pure water), a solvent control (0.01\% DMSO), PS-MP ( $10^{4}$ particles/L), methiocarb $(1 \mathrm{mg} / \mathrm{L})$, and a co-exposure of $10^{4}$ particles/L and $1 \mathrm{mg} / \mathrm{L}$ methiocarb (mixture). The test concentration of $1 \mathrm{mg} / \mathrm{L}$ methiocarb was selected due to published $\mathrm{LC}_{50}$ values for rainbow trout (Oncorhynchus mykiss): the reported $\mathrm{LC}_{50}$ $(96 \mathrm{~h})$ values vary between $\mathrm{LC}_{50}=0.198 \mathrm{mg} / \mathrm{L}$ [36] and $\mathrm{LC}_{50}=4.82 \mathrm{mg} / \mathrm{L}$ [58]. However, Altinok et al. [2] found all fish in the experiment exposed to concentrations equal or less $3.75 \mathrm{mg} / \mathrm{L}$ survived over 2 months. The relatively high concentration of $1 \mathrm{mg} / \mathrm{L}$ was selected to have a high chance for methiocarb to cause effects in brown trout and to be able to observe potential modulation of these effects. Each aquarium contained 10 fish (in $15 \mathrm{~L}$ of the corresponding test medium) resulting in 30 fish per treatment (aquaria in triplicates) and 150 fish in total. To be able to consider potential confounding factors, the position of each treatment group within the blocks was randomized. Exposure took place in a thermo-constant chamber set to $7{ }^{\circ} \mathrm{C}$ with a light/dark cycle of $10 \mathrm{~h} / 14 \mathrm{~h}$ (tanks were shaded from direct light). Aeration of the tanks was ensured by glass pipettes, which were connected to compressed air via silicone tubes.

In all treatment groups, filtered tap water was used. For the PS-MP treatments, the defined volumes of the stock suspensions $(56,240$ particles $/ \mathrm{mL})$ were added. To avoid a loss of particles in the glass vessels containing the PS-MP suspensions, the vessels were rinsed four times. For each tank containing methiocarb, a stock solution $(15 \mathrm{mg} / \mathrm{L}$ methiocarb) was prepared as follows: $15 \mathrm{mg}$ methiocarb were dissolved in $1.5 \mathrm{~mL}$ DMSO (resulting in a concentration of $0.01 \%$ DMSO in the tanks), and subsequently, $1 \mathrm{~L}$ water was added. Finally, the solutions were stirred for 2 days to ensure a complete dissolution of methiocarb. To provide comparability between the groups, $0.01 \%$ DMSO was also added to the tanks which contained only PS-MP.

Fish were fed daily a defined portion ( $4 \%$ of body weight) of commercially available fish food $(0.8 \mathrm{~mm}$, Biomar, Brande, Denmark). After $48 \mathrm{~h}$ and $72 \mathrm{~h}, 2.5 \mathrm{~L}$ of the test medium of each aquarium was removed to get rid of feces and remains of food. Water parameters were measured at the beginning and the end of the experiment (average values: temperature $=7.0 \pm 0.3{ }^{\circ} \mathrm{C}, \mathrm{pH}=7.3 \pm 0.5$, oxygen concentration $=10.9 \pm 0.4 \mathrm{mg} / \mathrm{L}$, oxygen saturation $=94.7 \pm 2.4 \%$; conductivity $=489.8 \pm 15.8 \mu \mathrm{S} / \mathrm{cm}$; for detailed information, see Additional file 1: Tables S1 and S2). Nitrite $\left(\mathrm{NO}_{2}^{-}\right)$values did not exceed $0.2 \mathrm{mg} / \mathrm{L}$. 
After $24 \mathrm{~h}$, four animals (one fish of block 1 methiocarb, two fish of block 3 methiocarb, and one fish of block 2 mixture) were in very poor health conditions and had to be euthanized. Apart from these, no fish died during the experiment.

At the end of the experiment, fish were anesthetized and killed by an overdose of tricaine methanesulfonate ( $1 \mathrm{~g} / \mathrm{L} \mathrm{MS} 222$, buffered with $\mathrm{NaHCO}_{3}$ ). Subsequently, death of the animals was ensured by severance of the spine. Body weight and length of each animal were recorded prior to dissection $(2.96 \pm 1.01 \mathrm{~g} / 6.47 \pm 0.73 \mathrm{c}$ $\mathrm{m})$. For histological investigations, samples of gills and liver were transferred into fixative ( $2 \%$ glutardialdehyde diluted in $0.1 \mathrm{M}$ cacodylate buffer; $\mathrm{pH}$ 7.6) and stored at $4{ }^{\circ} \mathrm{C}$ until further processing. For biochemical analyses, samples of muscle ( $\mathrm{AChE}$ and $\mathrm{CbE}$ activity), brain (LPO analysis), gills (stress protein analysis), and a part containing muscle and kidney (for analysis of SOD activity) were immediately frozen in liquid nitrogen. Subsequently, samples for biochemical analyses were stored at $-80^{\circ} \mathrm{C}$.

In addition, 30 fish (kept in a 250-L tank during the experiment) were sampled in an analogous manner as lab control to be able to recognize possible effects of the exposure procedure (e.g. limited water volume) itself.

\section{Chemical analysis}

From each aquarium, $12 \mathrm{~mL}$ medium was taken at the beginning and the end of the experiment and frozen at $-20{ }^{\circ} \mathrm{C}$ until further processing. Samples of the three replicate tanks were analyzed separately by means of HPLC-ESI-MS/MS. Quantification was performed via liquid chromatography coupled to mass spectrometry (LC-MS/MS). As instrumentation, a PerkinElmer Series 200 LC system (PerkinElmer, Waltham, USA) consisting of two Series 200 micro-pumps, a Series 200 vacuum degasser, and a Series 200 autosampler was coupled to a QqLIT mass spectrometer SCIEX QTRAP 3200 (AB SCIEX, Darmstadt, Germany), and ionization was achieved via electrospray ionization (ESI) in positive mode (further information is provided in Additional file 1).

Separation was performed at $23{ }^{\circ} \mathrm{C}$ using an XSelectTM HSS T3 reverse phase column $(2.1 \mathrm{~mm} \times 50 \mathrm{~mm}$, $3.5 \mu \mathrm{m}$ particle size) from Waters (Milford, USA). Injection volume was $10 \mu \mathrm{L}$ and a gradient was run with a flow rate of $200 \mu \mathrm{L} / \mathrm{min}$. Eluents used for chromatographic separation were mixtures of methanol and water (Eluent A: $\mathrm{MeOH} / \mathrm{H}_{2} \mathrm{O}, 5: 95, \mathrm{v} / \mathrm{v}$; Eluent B: $\mathrm{MeOH} / \mathrm{H}_{2} \mathrm{O}, 95: 5$, $\mathrm{v} / \mathrm{v}$ ) additionally containing $5 \mathrm{mM} / \mathrm{L}$ ammonium formate $\left(\mathrm{NH}_{4} \mathrm{HCO}_{2}\right)$ and adjusted to $\mathrm{pH} 3$ with formic acid (further information is provided in Additional file 1).
A multiple reaction monitoring (MRM) method was used for quantification. The individual transitions and optimized MS parameters are stated in Additional file 1: Table S5.

Unless specified otherwise, all calculations were carried out via Microsoft Excel 2016. The developed method was validated regarding the limit of detection (LoD), the limit of quantification (LoQ), and the method precision and accuracy. LoD and LoQ were determined by application of the signal to noise $(\mathrm{S} / \mathrm{N})$ approach. The $\mathrm{S} / \mathrm{N}$ ratios of two calibration standards $(\beta=0.25 \mathrm{ng} / \mathrm{mL}$ and $0.5 \mathrm{ng} /$ $\mathrm{mL}$ ) were measured in triplicate, and their $\mathrm{S} / \mathrm{N}$ ratio was determined. LoD was defined as $\mathrm{S} / \mathrm{N}>3$, and LoQ with $\mathrm{S} / \mathrm{N}>9$. With the determined $\mathrm{S} / \mathrm{N}$ ratios, the theoretical LoD and LoQ were calculated as $\mathrm{LoD}=0.04 \mathrm{ng} / \mathrm{ml}$ and $\mathrm{LoQ}=0.13 \mathrm{ng} / \mathrm{mL}$ (more details are provided in Table S6 in Additional file 1). The lowest standard of the calibration $(0.25 \mathrm{ng} / \mathrm{mL})$ corresponds to the applied LoQ.

Concentrations of standards used for calibration ranged from 0.25 to $250 \mathrm{ng} / \mathrm{mL}$, and atrazine was used as an internal standard. Measurement precision was determined by multiple $(n=5)$ of three standards and the calculation of their concentration based on the obtained calibration. Mean concentrations, relative standard deviation (RSD), and accuracy are stated in Table S7 in Additional file 1. For quantification, calibration was measured in triplicate (before, in between, and after the samples). Samples were filtered via syringe filters (Carl Roth, SPARTAN $^{\circledR}$ regenerated cellulose, $0.2 \mu \mathrm{m}$ ) after dilution $(1: 25 ; 1: 100 ; \mathrm{V} . \mathrm{V})$ with type 1 water and prior to their measurement.

\section{Determination of oxidative stress level Activity of SOD}

The SOD activity (Cu/Zn SOD, Mn SOD, and Fe SOD) in muscle/kidney samples was analyzed with the Cayman Chemical superoxide dismutase assay kit (item no. 706002, Cayman Chemical Company, Ann Arbor, USA) in 96-well plates. To remove any blood residues, samples were rinsed in phosphate-buffered saline (PBS; pH 7.4) before they were frozen in liquid nitrogen. The dilution of the final samples was 1:150. In the assay, superoxide radicals are generated with xanthine oxidase and hypoxanthine. Subsequently, the superoxide radicals are detected with tetrazolium salt. The absorbance at $450 \mathrm{~nm}$ was measured (Bio-Tek Instruments, Winooski VT, USA) after an incubation of $30 \mathrm{~min}$ at room temperature. All samples were analyzed in duplicates.

\section{Level of lipid peroxidases}

The level of lipid peroxides was quantified with the ferrous oxidation xylenol orange (FOX) assay. The assay was performed in a slightly modified way for 96 -well plates 
according to Hermes-Lima et al. [32] and Monserrat et al. [52]. For homogenization, the brains were 1:2 diluted with HPLC-grade methanol and subsequently centrifuged $\left(15,000 \mathrm{rcf}, 5 \mathrm{~min}, 4{ }^{\circ} \mathrm{C}\right)$. Supernatant was stored until the final assay at $-80^{\circ} \mathrm{C}$. The assay was performed in 96-well plates. Into each well, $50 \mu \mathrm{L}$ of $0.75 \mathrm{mM} \mathrm{FeSO}_{4}$ solution, $50 \mu \mathrm{L}$ of $75 \mathrm{mM}$ sulfuric acid, $50 \mu \mathrm{L}$ of $0.3 \mathrm{mM}$ xylenol orange solution, $40 \mu \mathrm{L}$ supernatant, and $10 \mu \mathrm{L}$ bidistilled water were added successively. Triplicates of each sample were tested. Furthermore, a sample blank without $\mathrm{FeSO}_{4}$ (replaced by bidistilled water) of each sample was measured to correct for potential $\mathrm{Fe}$ in the samples. After an incubation of $120 \mathrm{~min}$ at room temperature, the absorbance at $570 \mathrm{~nm}$ (ABS570) was measured (Bio-Tek Instruments, Winooski VT, USA). Afterward, in each well $1 \mu \mathrm{L}$ of $1 \mathrm{mM}$ cumene hydroperoxide solution $(\mathrm{CHP})$ was pipetted. The plates were incubated for another $30 \mathrm{~min}$ at room temperature, and a second measurement at $570 \mathrm{~nm}$ was conducted. The data of both measurements were related to a master blank $(200 \mu \mathrm{L}$ bidistilled water). Cumene hydroperoxide equivalents (CHPequiv./mg wet weight) were calculated using the following equation:

$$
\begin{aligned}
& \text { CHP equiv. } \\
& =\frac{\text { ABS570 sample }- \text { ABS570 sample blank }}{\text { ABS570 sample and CHP }- \text { ABS570 sample blank and CHP }} \\
& * \text { volume CHP } * \frac{\text { total volume in well }}{\text { sample volume }} * \text { dilution factor } \\
& =\frac{\text { ABS570 sample }- \text { ABS570 sample blank }}{\text { ABS570 sample and CHP }- \text { ABS570 sample blank and CHP }} \\
& * 1 * \frac{200}{40} * 2
\end{aligned}
$$

\section{Stress protein analysis}

Hsp70 quantification was performed as described by Dieterich et al. [13]. Samples were 1:3 diluted with extraction buffer $(80 \mathrm{mM}$ potassium acetate, $5 \mathrm{mM}$ magnesium acetate, $20 \mathrm{mM}$ HEPES, and $2 \%$ protease inhibitor at $\mathrm{pH}$ 7.5) and homogenized on ice. The samples were centrifuged $\left(20,000 \mathrm{rcf}, 10 \mathrm{~min}, 4{ }^{\circ} \mathrm{C}\right)$ and the supernatant was divided into two samples. The first was used to quantify the total protein content via Bradford assay [9]. Subsequently, the second sample (amount standardized to $40 \mu \mathrm{g}$ of total protein content) was separated via SDSPAGE (12\% acrylamide, $0.12 \%$ bisacrylamide, $30 \mathrm{~min}$ at $80 \mathrm{~V}$ plus $90 \mathrm{~min}$ at $120 \mathrm{~V}$ ). The proteins were blotted on a nitrocellulose membrane and immuno-stained with a monoclonal $\alpha$-Hsp70 IgG (Dianova, Hamburg, Germany) followed by a secondary peroxidase-coupled $\alpha$-IgG (Jackson Immunoresearch, West Grove, PA). The optical volume (area $\times$ average pixel intensity) of the protein bands was quantified (Image Studio Lite, 4.0.2.1, LiCor Biosciences, Lincoln, USA) and put into relation to an internal Hsp70 standard.

\section{Analysis of neurotoxicity}

For the analysis of the activity of $\mathrm{AChE}$ and two $\mathrm{CbE}$, muscle tissue was diluted 1:5 in Tris-LS buffer $(20 \mathrm{mM}$ Tris $_{\text {base }}, 20 \mathrm{mM} \mathrm{NaCl}$, inhibitor mix, pH 7.3) and homogenized. After centrifugation (5000 rcf, $10 \mathrm{~min}, 4{ }^{\circ} \mathrm{C}$ ), $50 \%$ glycerol was added to the supernatant $(1 / 4$ of the amount of the supernatant), and the mixture was frozen at $-20{ }^{\circ} \mathrm{C}$. The protein content in the samples was determined with the Lowry method modified by Markwell et al. [48]. The AChE-activity was measured spectrophotometrically at $405 \mathrm{~nm}$ (Bio-Tek Instruments, Winooski VT, USA) according to Ellman et al. [18] and modified by Rault et al. [61]. CbE activity was determined with the substrates $5 \mathrm{mM}$ 4-nitrophenol acetate (pnpa) and $5 \mathrm{mM}$ 4-nitrophenyl valerate (pnpv) described by Sanchez-Hernandez et al. [67]. In all assays, samples were analyzed in triplicates. The data were related to the total protein amount (specific activity per milligram total protein content). One unit is described as $1 \mu \mathrm{mol}$ substrate hydrolyzed per minute.

\section{Histopathology}

Liver and gill samples were fixed in $2 \%$ glutardialdehyde diluted in $0.1 \mathrm{M}$ cacodylate buffer $(\mathrm{pH}$ 7.6) and stored at $4{ }^{\circ} \mathrm{C}$ for at least 4 weeks. Prior to further processing, gill samples were decalcified in a $1: 2$ mixture of $100 \%$ formic acid and $70 \%$ ethanol. All samples were rinsed three times for $10 \mathrm{~min}$ in $0.1 \mathrm{M}$ cacodylate buffer and subsequently three times for $15 \mathrm{~min}$ in $70 \%$ ethanol. Dehydration of the samples and embedding into paraffin were achieved in an automated tissue infiltrator (TP 1020, Leica Wetzlar, Germany). With a sledge microtome (SM 2000 R, Leica Wetzlar, Gemany), 3- $\mu$ m-thick histological sections were cut. Sections were stained (1) with hematoxylin-eosin (HE) which visualizes nuclei, cytoplasm muscles, and connective tissue and (2) with alcian bluePAS by which glycogen and mucus were stained. In a first step, the slides were evaluated qualitatively to identify pathologies. In a second step, the slides were examined semi-quantitatively in an observer blinded way. The samples were categorized into five classes (1: control; 2: slight reactions; 3: medium reactions; 4: strong reactions; 5: destruction) as suggested by Triebskorn et al. [75]. Detailed definitions of the five categorizes are provided in Additional file 1: Table S8. 


\section{Statistical analysis}

Data analysis was performed with $\mathrm{JMP}^{\circledR}$ 14.0.0 (SAS Institute Inc., North Carolina, USA). Standard distribution of the data was checked with the Shapiro-Wilk test. Homogeneity of variance was checked with the Levene's test. If necessary, data were transformed (AChE: root, weight: third root, SOD: fifth root, Hsp70: natural logarithm, Cbe-pnpa: $1 / \times$, Cbe-pnpv: seventh root). Using a $t$ test for all investigated parameters, we ensured that there were no significant differences between the control and the solvent control. Subsequently, the other treatments were compared to the solvent control. In addition to the comparison to the solvent control, the PS-MP and the methiocarb treatments were compared to the mixture treatment. Comparisons with the lab control were conducted only qualitatively and were not included in the mathematical analyses.

The base $\alpha$-level was set to 0.05. Parametric data were analyzed with a nested ANOVA including 'block' as nesting factor. This allows considering potential confounding factors and avoiding pseudo-replication. The comparison between the single groups was made with Tukey HSD. The data of the activity of $\mathrm{CbE}$ with the substrate pnpa could not be transformed to reach homoscedasticity. Thus, a Welch ANOVA was performed to analyze the effect on the activity of CbE-pnpa mathematically. Frequency data were analyzed with likelihood ratio analysis and a post-hoc Bonferroni-Holm correction. Detailed values of the tests are given in Additional file 1: Table S9.

\section{Credibility of data}

The information on the fulfillment of the criteria for reporting and evaluation of ecotoxicity data (CRED) proposed by Moermond et al. [51] is provided in Additional file 1 .

\section{Results}

\section{Chemical analyses}

At the beginning and the end of the experiment, in both control groups, the methiocarb concentrations in the water phase were below the applied quantification limit (LoQ) of $0.25 \mu \mathrm{g} / \mathrm{L}$ (Table 2). In the PS-MP exposure, no methiocarb in the water phase could be detected ( $<$ LoQ). In both exposure groups with methiocarb (methiocarb and mixture), the measured concentrations in the water phase at the beginning of the experiment were $50 \%$ of the nominal concentrations. After $96 \mathrm{~h}$, in the treatment group with solely methiocarb, the concentration was further reduced by approximately $50 \%$, and in the mixture treatment by $34 \%$.

\section{Mortality and weight}

After $48 \mathrm{~h}$, three of the fish exposed to methiocarb and one of the fish exposed to the mixture had to be euthanized due to their poor health conditions. Apart from that, no mortality occurred during the experiment. The total mortality was $2.67 \%$. Weight (overall mean $2.96 \pm 1.01 \mathrm{~g})$ did not differ between the treatment groups (Table $3 ; p=0.3384$ ).

\section{Oxidative stress}

To assess the oxidative stress level, SOD activity and the degree of LPO were investigated. No difference $(p=0.5136)$ between SOD activity in the different treatment groups was found (Table 3 ). The degree of LPO of the exposure groups was comparable to the solvent control $(p=0.5770)$. For both tested endpoints, neither PS-MP nor methiocarb nor the mixture caused oxidative stress.

\section{Proteotoxicity}

The analysis of the Hsp70 level did not reveal any differences between control, solvent control, and exposure groups (Table $3 ; p=0.7922$ ).

\section{Neurotoxicity}

No difference in the activity of AChE occurred between solvent control and treatment group with PS-MP $(p=0.8192)$. However, the methiocarb and the mixture of methiocarb and PS-MP led to a significantly reduced

Table 2 Nominal and measured concentrations of methiocarb in the water phase of the different treatment groups

\begin{tabular}{llll}
\hline Treatment group & $\begin{array}{l}\text { Nominal concentration } \\
(\boldsymbol{\mu g} / \mathbf{L})\end{array}$ & $\begin{array}{l}\text { Measured concentration at start } \\
\text { of experiment }(\boldsymbol{\mu g} / \mathbf{L})\end{array}$ & $\begin{array}{l}\text { Measured concentration } \\
\text { at end of experiment } \\
(\boldsymbol{\mu g} / \mathbf{L})\end{array}$ \\
\hline Control & 0 & $<0.25$ & $<0.25$ \\
Solvent control & 0 & $<0.25$ & $<0.25$ \\
PS-MP (104 particles/L) & 0 & $<0.25$ & $<0.25$ \\
Methiocarb & 1000 & $463 \pm 32$ & $237 \pm 59$ \\
Mixture PS-MP+ methiocarb & 1000 & $469 \pm 133$ & $308 \pm 76$ \\
\hline
\end{tabular}

Displayed are the arithmetic mean \pm standard deviation of the three aquaria. The applied limit of quantification was $0.25 \mu \mathrm{g} / \mathrm{L}$ methiocarb 
Table 3 Summary of data for the investigated endpoints

\begin{tabular}{lcccccc}
\hline & Lab control & Control & Solvent control & PS-MP & Methiocarb & Mixture \\
\hline Weight (g) & $4.02 \pm 1.09$ & $2.49 \pm 0.66$ & $2.89 \pm 0.87$ & $3.21 \pm 0.91$ & $2.95 \pm 1.27$ & $3.30 \pm 1.06$ \\
SOD (U/mL) & $92.71 \pm 26.12$ & $105.29 \pm 28.81$ & $106.50 \pm 24.22$ & $106.66 \pm 29.69$ & $99.88 \pm 31.59$ & $99.43 \pm 35.37$ \\
FOX (CHP-Equiv.) & $2.17 \pm 1.26$ & $2.56 \pm 1.09$ & $1.97 \pm 1.17$ & $1.69 \pm 1.21$ & $1.83 \pm 1.52$ & $1.60 \pm 1.39$ \\
Hsp70 (relative grey value) & $1.71 \pm 0.29$ & $1.84 \pm 0.29$ & $1.78 \pm 0.29$ & $1.72 \pm 0.26$ & $1.77 \pm 0.30$ & $1.71 \pm 0.27$ \\
AChE (mU/mg protein) & $69.32 \pm 11.55$ & $88.38 \pm 24.98$ & $77.37 \pm 18.39$ & $73.93 \pm 20.28$ & $31.48 \pm 11.38$ & $32.38 \pm 11.64$ \\
CbE-pnpa (mU/mg protein) & $82.20 \pm 9.16$ & $79.13 \pm 10.83$ & $79.10 \pm 11.38$ & $76.68 \pm 7.90$ & $45.52 \pm 5.74$ & $44.48 \pm 5.01$ \\
CbE-pnpv (mU/mg protein) & $60.60 \pm 11.14$ & $53.89 \pm 12.38$ & $54.01 \pm 12.94$ & $49.59 \pm 10.46$ & $9.10 \pm 3.24$ & $9.05 \pm 1.91$ \\
\hline
\end{tabular}

All data are given as arithmetic mean \pm standard deviation

activity of AChE in comparison to the solvent control and PS-MP alone (Fig. 2).

The activity of AChE in the methiocarb-exposed fish was 59\% reduced compared to the solvent control $(p<0.001)$. In fish exposed to the mixture of PS-MP and methiocarb, the activity of AChE was reduced by $58 \%$ compared to the solvent control $(p<0.001$; Table 3$)$.

Between fish exposed to methiocarb alone and methiocarb plus PS-MP, no differences were found ( $p=0.9951)$.

The activity of CbE-pnpa was also inhibited by methiocarb and the mixture treatment (Fig. 2; DMSO/ PS-MP: $p=0.9357$; DMSO/methiocarb, DMS0/mixture and PS-MP/mixture: $p<0.001$; methiocarb/mixture: $p=0.8531$ ). The activity of the CbE-pnpa was not altered by PS-MP alone. Methiocarb alone reduced the activity compared to the solvent control by $42 \%$, and the mixture by $44 \%$.

Even more pronounced was the inhibition of $\mathrm{CbE}$ with the substrate pnpv: compared to the solvent control, the activity was reduced by $83 \%$ both in methiocarb-exposed fish and for fish in the mixture treatment (Fig. 2; DMSO/ mixture, PS-MP/mixture: $p<0.0001$; methiocarb $/ \mathrm{mix}$ ture: $p=0.7609$ ). Again, PS-MP alone had no influence on the activity of CbE-pnpv. Beside the clear effect of the different treatments, the treatment nested in the block had a significant effect $(p=0.0322)$.

\section{Histopathology \\ Liver}

Healthy liver tissue consists of large bright cells containing high amounts of glycogen (Fig. 3a, b). Fish from the lab control, control, solvent control, and exposure with PS-MP showed in some cases inflammations and even focal necrosis. In fish exposed to methiocarb alone or the mixture treatment, a reduction of the glycogen stores became obvious (Fig. 3d) resulting in atrophic cells and enlarged intercellular spaces. Furthermore, in both groups containing methiocarb, vacuolization and inflammations occurred cumulatively, and in the majority of samples small zones (single cell or few cells) with karyopyknosis and focal necrosis were found (Fig. 3c). In all investigated samples, the proportion of necrotic tissue was $<10 \%$. Semi-quantitative analyses showed a very similar condition of fish from the control, solvent control, and exposure with PS-MP, whereas livers of fish exposed to methiocarb or the mixture treatment showed significantly stronger reactions (Fig. 3g; DMSO/PS-MP: $p=0.0577, \mathrm{DMSO} /$ methiocarb, DMSO/mixture, $\mathrm{PS}-\mathrm{MP} /$ mixture: $p<0.0001$, methiocarb/mixture: $p=0.2396$ ).

\section{Gills}

Observed pathological alterations in gills of brown trout included hyperplasia and hypertrophy of chloride and pillar cells resulting, in some cases, in lamellar fusion (Fig. 3e, f). Furthermore, an increase of mucus secreting cells, lifting of epithelia, edema, and even necrosis in small areas occurred. Most of these symptoms were observed in the methiocarb and the mixture treatment groups. Lamellar fusion occurred on small parts of the lamellae of circa $20 \%$ in the lab control, the control, and the solvent control samples as well as $10 \%$ of the MP exposure. In the methiocarb and mixture groups, it was considerably more common with $47 \%$ (methiocarb) and $42 \%$ (mixture). Edemas occurred only in $19 \%$ of the methiocarb group and $14 \%$ of the mixture exposed group. They were located at the inner side of the secondary lamellae.

Semi-quantitative analysis revealed a significantly worse condition of the two treatment groups containing methiocarb compared to the solvent control and fish exposed solely to PS-MP (Fig. 3h; DMSO/PS-MP: $p=0.4562, \mathrm{DMSO} /$ methiocarb, $\mathrm{DMSO} /$ mixture, $\mathrm{PS}-\mathrm{MP} /$ mixture: $p<0.0001$, methiocarb/mixture: $p=0.7266$ ). Gill sections were classified in categories 1-4 of 5 categories in total. No difference was found between the control groups and the group containing solely PS-MP. 

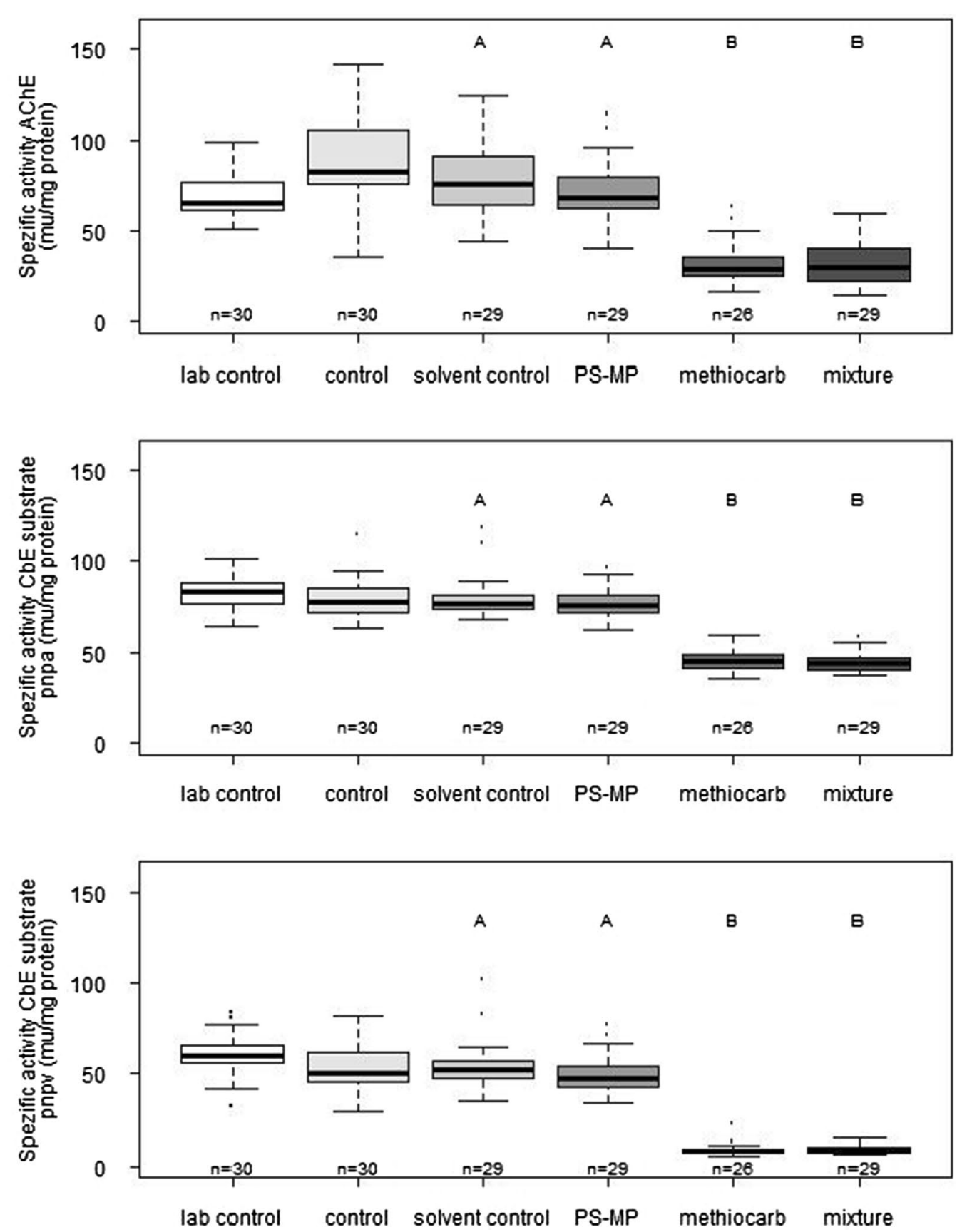

Fig. 2 Specific activity of acetylcholinesterase and carboxylesterases with substrate pnpa and pnpv in muscular tissue of brown trout. The box plots display the median, the 25th and 75th percentiles as well as minimum and maximum values (whiskers); the dots indicate outliers. Different letters indicate significant differences. Methiocarb and mixture significantly reduced the AChE activity as well as CbE-pnpa and CbE-pnpv activity $(p<0.0001)$

\section{Discussion}

In the present study, the effects of PS-MP and the pesticide methiocarb either applied alone or in their binary mixture were investigated in juvenile brown trout.

\section{General considerations concerning the conducted} experiment

The measured methiocarb concentrations corresponded to approximately half of the nominal concentration in 
(See figure on next page.)

Fig. 3 a Control status of liver of juvenile trout with homogenous tissue with large hepatocytes. $\mathbf{b}$ The hepatocytes contain a huge amount of glycogen. c Occurring reactions in the liver were inter-alia inflammations (IN), vascular dilation (VD) and focal necrosis (FN). d Furthermore, reduced glycogen amount and increased intercellular (IC) spaces in liver samples were found. e Control status of gills of juvenile trout with regularly shaped secondary lamellae. $\mathbf{f}$ Reaction status of gills showing hypertrophy (HT) and hyperplasia (HP) of cells, lamellar fusion (LF) as well as edema (OE). $\mathbf{a}, \mathbf{c}, \mathbf{e}, \mathbf{f}$ Hematoxylin-eosin staining; $\mathbf{b}, \mathbf{d}$ Alcian blue-PAS staining. $\mathbf{g}, \mathbf{h}$ Semi-quantitative analyses of liver ( $\mathbf{g}$ ) and gills (h). Category 1 represents an excellent health status, 3 a reaction status and 5 a destruction status. 2 and 4 are intermediary classes. No section was assigned to category 5 . Statistical comparison showed significantly more reactions in liver and gill samples of methiocarb or methiocarb plus PS-MP exposed fish. Different letters indicate significant differences $(p<0.0001)$

the methiocarb and mixture groups at the beginning of the experiment and 24\% (methiocarb group) and 31\% (mixture group) at the end. Considering the standard deviations, however, there is no relevant difference in the methiocarb concentration of methiocarb and mixture treatment group at the end of the experiment. Methiocarb has a comparable low persistence in laboratory aerobic soil-water systems [3]. The degradation of methiocarb is $\mathrm{pH}$-dependent and higher under alkaline conditions. The main metabolites are methiocarb phenol and methiocarb sulfoxide phenol. The dissipation halflife $\left(\mathrm{DT}_{50}\right)$ of methiocarb in water at $\mathrm{pH} 7$ is 24 days and 0.21 days at $\mathrm{pH} 9$ [16]. Thus, a degradation of methiocarb in this experiment was likely, but occurred to a greater extent as it could have been assumed in an environment with a pH of 7.3. During the experiment, beside the abiotic degradation, a metabolization by the fish may have contributed to the decreased methiocarb concentration after $96 \mathrm{~h}$. In humans, mainly cytochrome p450 and flavin-containing monooxygenases in liver and kidney contribute to the metabolism of methiocarb $[30,76]$. For longer exposure to methiocarb, regular exchange of the water with freshly prepared methiocarb solutions or a flow-through exposure is recommended.

\section{Do PS-MP affect juvenile brown trout?}

In juvenile brown trout, none of the investigated parameters were affected by $10^{4}$ polystyrene particles/L. In the past, MP were found to cause oxidative stress in fish [44, $57,59]$. In contrast to these results, other studies found either no effects $[28,45,54]$ or effects in only some of the investigated endpoints for oxidative stress [4, 14, 27, 47]. The oxidative defense system is complex and consists of enzymatic [e.g. SOD, catalase (CAT), glutathione reductase] and non-enzymatic compounds [46]. In addition, the types of investigated polymers, their concentrations, their potential additives as well as the size of the used MP highly vary in the different studies. Jeong et al. [35] analyzed the influence of the particle size on oxidative stress responses and showed that there is a clear connection to this parameter: smaller particles cause more oxidative stress. In general, however, the data are still far too limited and experimental designs of the studies are too variable to decide on whether or not MP cause oxidative stress and, in case of any influence, which pathways are affected.

To the best of our knowledge, the present study is the first that investigated potential proteotoxic effects of MP. In the tested concentration, no effect of PS-MP on the stress protein level (Hsp70) was found in brown trout after $96 \mathrm{~h}$ exposure.

Also, the activity of $\mathrm{AChE}$ and two investigated $\mathrm{CbE}$ was not altered after exposure to PS-MP. In the past, several studies reported significant reductions about $20 \%$ of AChE activity in common goby (Pomatoschistus microps) after exposure to $184 \mu \mathrm{g} / \mathrm{L}$ polyethylene (PE; $1-5 \mu \mathrm{m}$ ) for $96 \mathrm{~h}[28,45,54]$. Under the same test conditions, Ferreira et al. [27] only found a reduction of AChE activity by $13 \%$ in common goby. Furthermore, a decrease of AChE activity in Amazonian discus fish Symphysodon aequifasciatus was observed after exposure to $200 \mu \mathrm{g} / \mathrm{L}$ fluorescent PE $(70-88 \mu \mathrm{m})$ for 30 days [80]. In red tilapia (Oreochromis niloticus), an even higher inhibition of AChE by $37.7 \%$ was found after exposure to PS nanoplastics $(0.1 \mu \mathrm{m})$ in concentrations of circa $1.8 \times 10^{6}, 1.8 \times 10^{7}$, and $1.8 \times 10^{8}$ particles/L for 14 days [14]. Chen et al. [11] did not find any neurotoxic effect of PS-MP $(45 \mu \mathrm{m}, 20$ particles $/ \mathrm{mL}$ ) in zebrafish (Danio rerio) but reported a significant reduction of AChE activity by $40 \%$ after exposure to a high concentration of PS nanoplastics $(50 \mathrm{~nm}$, $1.5 \times 10^{10}$ particles $\left./ \mathrm{mL}\right)$. In general, the mode of action of how MP might cause neurotoxicity remains unclear. In addition to the type of polymer (including different additives), the particle size also seems to be of importance in this context, since neurotoxic effects were mainly found in studies using very small micro- or even nanoplastics. Furthermore, Ding et al. [14] reported accumulation of nanoplastics in the brain of red tilapia. These findings are supported by a study of Mattsson et al. [49] who demonstrated that polystyrene nanoplastics are capable of penetrating the blood-brain barrier of Crucian carp (Carassius carassius). The plastic particles we used in the present study were $<50 \mu \mathrm{m}$ with only a low number of particles $<1 \mu \mathrm{m}$ which might explain the lack of influence on neurotoxicity. 

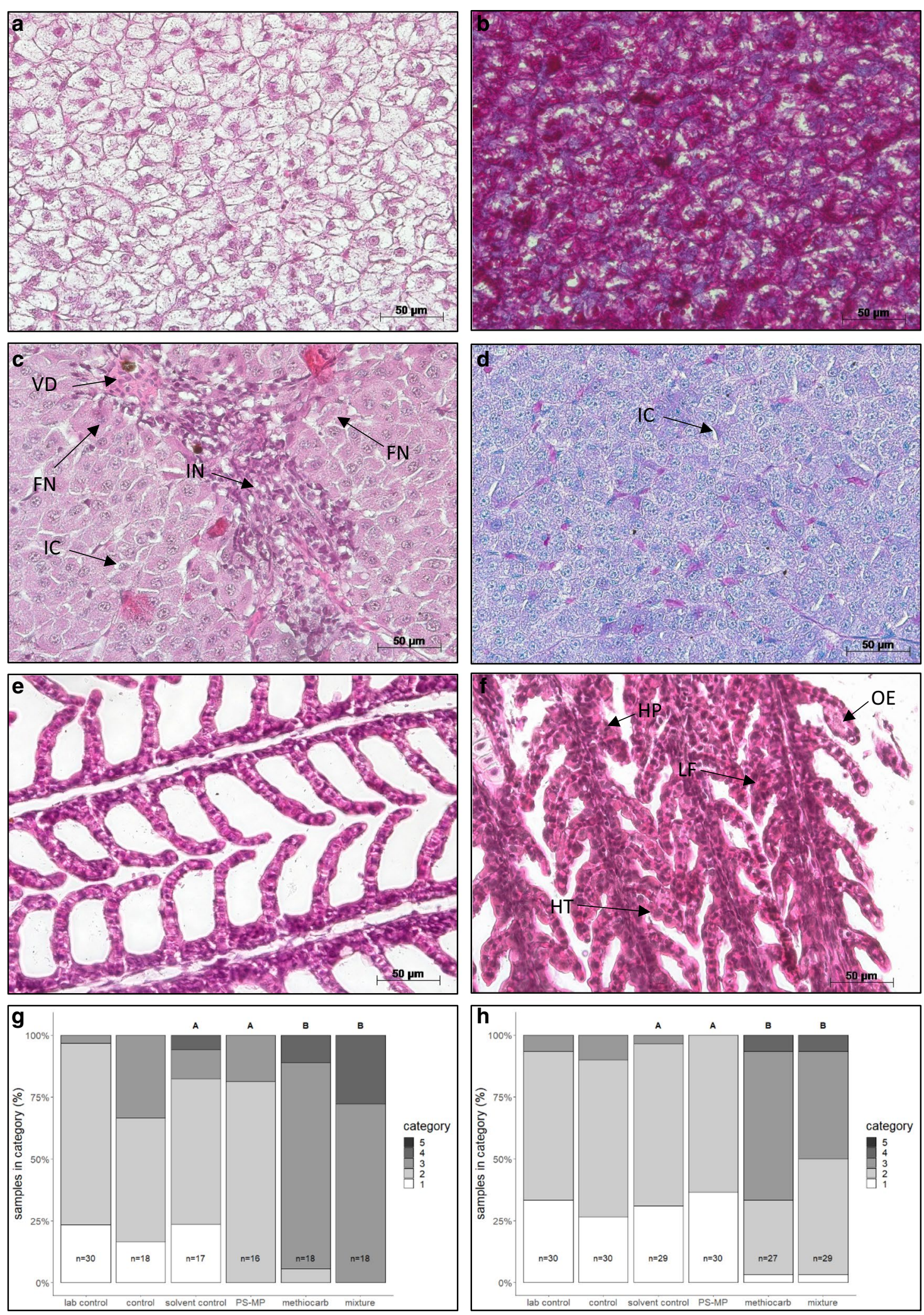
In the present study, no alterations in the histopathological status of the liver and gills were found in fish exposed to PS-MP alone when compared to the solvent control group. Also, low-density PE (125-250 $\mu \mathrm{m})$ caused no alterations in the liver of zebrafish after 3 weeks of exposure [60]. Furthermore, besides effects on the intestine Lei et al. [41] did not find any alterations in gills, liver, and kidney of zebrafish exposed to polyamide (PA), polypropylene (PP), polyvinyl chloride (PVC), and $\mathrm{PE}$ (each $\sim 70 \mu \mathrm{m}$ in a concentration up to $10 \mathrm{mg} / \mathrm{L}$ ) for 10 days. Moreover, in silver barb fry (Barbodes gonionotus) no histopathological reactions were caused by PVC $(0.1-1000 \mu \mathrm{m} ; 0.2,0.5$ and $1.0 \mathrm{mg} / \mathrm{L})$ fragments besides a slight thickening of the intestinal mucosal epithelium [65]. In addition, Lei et al. [41] did not find any effect of PS-MP $(0.1,1.0$ and $5 \mu \mathrm{m}$ up to $10 \mathrm{mg} / \mathrm{L})$ on tissue integrity of intestine, gills, kidney, and liver of zebrafish after 10 days of exposure. In contrast, $\mathrm{Lu}$ et al. [44] observed early inflammation responses as well as lipid droplets in the liver of zebrafish after exposure to $5 \mu \mathrm{m}$ polystyrene particles in a concentration of $2.9 \times 10^{4}$ particles/L for 3 weeks. In Japanese medaka (Oryzias latipes) severe glycogen depletion and fatty vacuolization in the liver occurred, but no alterations were found in gonads after exposure to PE $(<0.5 \mathrm{~mm})$ for 2 months $[63,64]$. Karami et al. [37] exposed African catfish (Clarias gariepinus) to low-density PE $(<60 \mu \mathrm{m})$ for $96 \mathrm{~h}$. They observed hyperplasia and sloughing and even necrosis in gills at a concentration of $50 \mu \mathrm{g} / \mathrm{L}$ and even more severe reactions like desquamation of cells at a concentration of $500 \mu \mathrm{g} / \mathrm{L}$. In addition, the degree of tissue damage in the liver of the fish was increased after exposure to low-density PE in a concentration of $500 \mu \mathrm{g} / \mathrm{L}$ [37]. The sizes of the investigated MP are an important parameter since small MP or nanoplastic particles can be taken up by cells $[6,14$, 49]. In general, there is no evidence for a uniform pattern under which conditions histopathological changes may occur after exposure to MP.

Reports of the environmental concentration of MP in surface waters of a size $<50 \mu \mathrm{m}$ are rather scarce possibly due to difficulties with the sampling and detection methodology [12, 74]. Nevertheless, reported results of MP indicate higher concentrations of smaller MP compared to larger ones [74]. Measured MP concentrations in the environment varied between 0.5 and 3.1 particles/L $(>20 \mu \mathrm{m})$ and 100 and 900 particles/L $(>4 \mu \mathrm{m})$ [72, 74]. In the present study, the concentration of PS particles was $10^{4}$ and therefore higher than the environmental concentration. Our study does not indicate a risk for brown trout at environmental concentrations. Nevertheless, to exclude potential negative effects of MP on brown trout other experiments with longer exposure time and other polymer types are necessary.

\section{Does methiocarb affect juvenile brown trout?}

Three fish exposed to methiocarb as sole pollutant showed strong behavioral reactions after $24 \mathrm{~h}$ and had to be euthanized. After $96 \mathrm{~h}$, all other fish exposed to methiocarb also exhibited behavioral abnormalities like slower swimming and reduced escape behavior. To the best of our knowledge, this is the first study that investigated the effects of methiocarb on brown trout. In the present study, weight of methiocarb-exposed fish was comparable to the control group. However, $96 \mathrm{~h}$ is a relatively short time to observe changes regarding this endpoint in brown trout. To our knowledge, no one has analyzed the effect of methiocarb on stress proteins so far, and rarely proteotoxic effects of carbamate pesticides were studied in general. In the present study, methiocarb did not cause any alteration of Hsp70 level of juvenile brown trout. Samples of brown trout showed neither an increase of SOD nor an altered amount of LPO exposure to methiocarb. An increase of LPO and an alteration of reduced glutathione level were found in male Wistar rats fed with 2, 10, and $25 \mathrm{mg} / \mathrm{kg}$ methiocarb [55]. Ozden and Alpertunga [55] found the highest malondialdehyde level in the brain and explained their finding by the comparably large amount of fatty acids in this organ. In another study, Ozden et al. [56] found also an increase of glutathione as well as of the activities of SOD, CAT, and glutathione peroxidase in male Wistar rats after administration of $25 \mathrm{mg} / \mathrm{kg}$ methiocarb.

The observed reactions of fish can be seen as a consequence of the AChE inhibition by methiocarb. Acetylcholine (ACh) accumulates in the synaptic cleft leading to a cholinergic crisis [66]. In the present study, methiocarb led to a reduction of the AChE activity by $59 \%$ in the tested juvenile brown trout. The mode of action of carbamate pesticides is based on carbamylation of AChE and, thereby, inhibition of its ability to hydrolyze acetylcholine [29]. Therefore, it could have been expected that methiocarb reduces the activity of AChE also in brown trout. Comparable effects were observed by Essawy et al. [21] in the land snail Eobania vermiculata in which AChE activity was reduced up to $69.3 \%$ by methiocarb. Carboxylesterases play an important role in pesticide detoxification [81]. Sanchez-Hernandez et al. [67] suggested that $\mathrm{CbE}$ might act as the biochemical barrier for organophosphate pesticides in Lumbricus terrestris. Maymó et al. [50] found that esterase activity is higher in western flower thrips (Frankliniella occidentalis) with increased resistance against methiocarb. To our knowledge, no studies about the effect of methiocarb on AChE and $\mathrm{CbE}$ activities in fish were performed up to date. However, in the present study, $\mathrm{CbE}$ as well as AChE were inhibited by methiocarb and no protective effect became obvious. This might possibly be related to the fact that 
the methiocarb concentration was rather high and all three enzymes were inhibited and the protective effect of $\mathrm{CbE}$ ceased.

After exposure to methiocarb, prominent histopathological alterations became evident in livers and gills of the exposed fish. Altinok et al. [2] observed similar effects in gills of rainbow trout exposed to 3.75 and $7.5 \mathrm{mg} / \mathrm{L}$ methiocarb. After 96 h, symptoms like lamellar edema, lifting of epithelia, telangiectasis, increased cytoplasmic granularity, and lamellar fusion occurred. Effects were reversible in concentrations below $3.75 \mathrm{mg} / \mathrm{L}$. In fish livers, Altinok et al. [2] found necrosis. Altinok et al. [2] assumed that the alterations are caused by ionic imbalance due to inhibition of AChE activity. In a follow-up study, Altinok and Capkin [1] found no histopathological alterations in liver, kidney, brain, and spleen of rainbow trout after exposure to 2.5 or $3.75 \mathrm{mg} / \mathrm{L}$ methiocarb for 21 days. However, in gills of rainbow trout lamellar lifting occurred when fish were exposed to $3.75 \mathrm{mg} / \mathrm{L}$ methiocarb for 21 days [1]. Brown trout seem to be more sensitive to methiocarb than rainbow trout as indicated by the more severe effects in the present study. This was also shown in the past for other environmental stressors [69].

The tested methiocarb concentration $(1 \mathrm{mg} / \mathrm{L})$ was considerably higher than the average surface water concentration of 6-40 ng/L in an EU-wide monitoring campaign [43]. The study was designed to investigate acute effects of methiocarb and a potential modulation of these effects by PS-MP. Nevertheless, the strong acute effects of methiocarb in brown trout elucidate the need for experiments in which brown trout are exposed to methiocarb at environmentally relevant concentrations for a longer exposure time. Such experiments would allow to assess the current risk of methiocarb exposure for brown trout in the environment.

\section{Do PS-MP modulate the effects of methiocarb?}

When considering all investigated endpoints, fish exposed to the mixture of methiocarb and PS-MP showed the same reactions as fish exposed to methiocarb only. Weight as well as the stress protein level and the level of oxidative stress remained unchanged. However, the activity of $\mathrm{AChE}$ and $\mathrm{CbE}$ was significantly reduced in the mixture to almost the same extent as caused by methiocarb alone. Furthermore, the observed histopathological alterations in liver and gills in fish of the mixture treatment were comparable to those found in fish exposed only to the pesticide. Thus, the toxicity of methiocarb on brown trout was not modulated by PS-MP. The chemical analytics and the observed effects indicate that no relevant sorption of methiocarb to PS-MP occurred. It is possible that a modulation of the toxicity of methiocarb by PS-MP in the present study was hidden by the comparable strong effects caused by the relatively high methiocarb concentration. To the best of our knowledge, the interaction of carbamate pesticides and MP has not been investigated before. In their review, de Sá et al. [12] identified only 1 out of 59 studies where no interaction between MP and another tested contaminant was found. Ferreira et al. [27] reported that the effects of gold nanoparticles were not modulated by PE particles $(1-5 \mu \mathrm{m})$. Of course, de Sá et al. [12] could not account in their meta-analysis for the probable bias against publishing negative results. Multiple studies show that effects of different pollutants were decreased in combination with MP. For example, PS-MP alleviated the effects of 17 $\alpha$-ethinylestradiol (EE2) on locomotion in zebrafish [11]. Similar results were found after exposure of zebrafish larvae to EE2, phenanthrene and a mixture of both with PVC particles. In the presence of PVC particles, the expression of cytochrome P4501A and vitellogenin was reduced up to $48 \%$ for EE2 and by $33 \%$ for phenanthrene [70]. In general, a reduced toxicity of co-contaminants in the presence of MP might be explained by a decreased bioavailability of the chemicals due to sorption to the plastic particles. In the present study, chemical analyses revealed that the concentration of methiocarb was higher in the mixture treatment than in the groups exposed to methiocarb alone after $97 \mathrm{~h}$. Thus, it is probable that methiocarb did not sorb in considerable amounts to the plastic microparticles. In contrast to reports on a reduction of chemical-induced effects by MP, other studies conducted with MP in combination with chemicals found an intensification of such effects. For example, in common carp (Cyprinus carpio), MP increased the effects of paraquat on biochemical blood parameters. Thereby, higher concentrations of MP increased the toxicity [53]. Moreover, Fonte et al. [28] found a significant interaction between PE-MP and cefalexin. In the mixture of both, the effect of cefalexin on the predatory performance of common goby was increased at $20{ }^{\circ} \mathrm{C}$, but reduced at $25{ }^{\circ} \mathrm{C}$. In the present study, the toxicity of methiocarb was not enhanced by MP. Compared to the uptake pathway via the water, PS-MP seemed to have a negligible effect on the uptake of methiocarb in juvenile brown trout.

\section{Conclusion}

Based on the results of our study, we conclude that methiocarb heavily impairs the health of brown trout, whereas the studied PS-MP in a concentration of $10^{4}$ particles/L do not. It can also be excluded that the studied PS-MP modulate methiocarb-induced effects in brown trout in the tested concentrations. In general, literature provides a diverse and inconsistent image with respect to the capacity of MP to modulate the toxicity of environmental chemicals. Although our study 
does not speak for an environmental risk related to the investigated polystyrene particles and their interaction with the pesticide methiocarb, this study provides only a very small piece of knowledge for a defined type and size class of plastics and a single pesticide, and emphasizes the need of further research in this field.

\section{Supplementary information}

Supplementary information accompanies this paper at https://doi. org/10.1186/s12302-020-00327-4.

Additional file 1. Additional figures and tables.

\begin{abstract}
Abbreviations
AChE: Acetylcholinesterase; ABS570: Absorbance 570 nm; CAT: Catalase; CbE: Carboxylesterase; CHP: Cumene hydroperoxide; EE2: 17 a-Ethinylestradiol; Equiv: Equivalents; LoD: Limit of detection; LoQ: Limit of quantification; LPO: Lipid peroxidation; $\mathrm{LC}_{50}$ : Lethal concentration 50\%; MiWa: Microplastics in the water cycle; MP: Microplastics; PA: Polyamide; PE: Polyethylene; PET: Polyethylene terephthalate; PS: Polystyrene; PP: Polypropylene; PVC: Polyvinyl chloride; SOD: Superoxide dismutase.
\end{abstract}

\section{Acknowledgements}

We are deeply grateful to Prof. Dr. Martin Jekel for the initiation and coordination of the MiWa project. We thank Christoph Fahrenson (ZELMI, TU Berlin) for electron microscopic analyses. For proofreading of the manuscript, we thank Sarai Rosenberg and Dr. Sophie Schmieg. Furthermore, the authors wish to thank Dr. Katharina Peschke, Michael Ziegler, Stefanie Jacob, Sabrina Wilhelm, Dr. Simon Schwarz, Dr. Carla Lorenz, Dr. Paul Thellmann, Dr. Andreas Dieterich and Kathrin Leinmüller for discussion, technical assistance and assistance in the lab.

\section{Authors' contributions}

HS wrote the manuscript except for "Chemical analysis" section, which was written by SH. She contributed to the design of the experiment, conducted the experiment, analyzed (or supervised analyses) of stress-proteins and oxidative stress. SH performed the chemical analysis and revised the whole manuscript. SK and TPK revised the entire manuscript. FR analyzed the level of lipid peroxidation as well as the acetylcholinesterase and carboxylesterase activity. KR performed the histopathological analysis and parts of the analysis of the SOD activity; ASR provided the microplastic particles and revised the whole manuscript, HRK and RT designed the experiment, contributed to the interpretation of data and revised the entire manuscript. All authors read and approved the final manuscript.

\section{Funding}

The experiment was conducted within the joint project MiWa (Microplastics in the water cycle-sampling, sample preparation, analytics, occurrence, removal, and assessment) founded by the German Federal Ministry of Education and Research (Support Code: 02WRS1378).

\section{Availability of data and materials}

The datasets used and analyzed during the current study are available from the corresponding author on request.

\section{Ethics approval and consent to participate}

The experiment was approved by the animal welfare committee of the Regional Council of Tübingen, Germany (authorization number ZO 2/16).

\section{Consent for publication}

Not applicable.

\section{Competing interests}

The authors declare that they have no competing interests.

\section{Author details}

${ }^{1}$ Animal Physiological Ecology, University of Tübingen, Auf der Morgenstelle 5, 72076 Tübingen, Germany. ${ }^{2}$ Hochschule Fresenius, University of Applied Sciences, Institute for Analytical Research (IFAR), Limburger Str. 2, 65510 Idstein, Germany. ${ }^{3}$ Chair of Water Quality Control, Technische Universität Berlin, Sekr. KF 4, Str. des 17. Juni 135, 10623 Berlin, Germany. ${ }^{4}$ German Environment Agency (UBA), Section II 3.1 (National and International Development of Drinking Water Quality and Resource Protection), Schichauweg 58, 12307 Berlin, Germany. ${ }^{5}$ Steinbeis Transfer Center for Ecotoxicology and Ecophysiology, Blumenstr. 13, 72108 Rottenburg, Germany.

Received: 20 December 2019 Accepted: 8 March 2020

Published online: 23 March 2020

\section{References}

1. Altinok I, Capkin E (2007) Histopathology of rainbow trout exposed to sublethal concentrations of methiocarb or endosulfan. Toxicol Pathol 35(3):405-410

2. Altinok I, Capkin E, Karahan S, Boran M (2006) Effects of water quality and fish size on toxicity of methiocarb, a carbamate pesticide, to rainbow trout. Environ Toxicol Pharmacol 22(1):20-26

3. Arena M, Auteri D, Barmaz S, Brancato A, Brocca D, Bura L, Cabrera LC, Chiusolo A, Civitella C, Marques DC, Crivellente F, Ctverackova L, Lentdecker CD, Egsmose M, Erdos Z, Fait G, Ferreira L, Greco L, Ippolito A, Istace F, Jarrah S, Kardassi D, Leuschner R, Lostia A, Lythgo C, Magrans JO, Medina P, Mineo D, Miron I, Molnar T, Padovani L, Morte JMP, Pedersen R, Reich H, Sacchi A, Santos M, Serafimova R, Sharp R, Stanek A, Streissl F, Sturma J, Szentes C, Tarazona J, Terron A, Theobald A, Vagenende B, Dijk $J V$, Villamar-Bouza $L$ (2018) Peer review of the pesticide risk assessment of the active substance methiocarb. EFSA J 16:10

4. Avio CG, Gorbi S, Milan M, Benedetti M, Fattorini D, d'Errico G, Pauletto M, Bargelloni L, Regoli F (2015) Pollutants bioavailability and toxicological risk from microplastics to marine mussels. Environ Pollut 198:211-222

5. Bakir A, Connor IA, Rowland SJ, Hendriks AJ, Thompson RC (2016) Relative importance of microplastics as a pathway for the transfer of hydrophobic organic chemicals to marine life. Environ Pollut 219:56-65

6. Batel A, Linti F, Scherer M, Erdinger L, BraunbeckT (2016) Transfer of benzo[a]pyrene from microplastics to Artemia nauplii and further to zebrafish via a trophic food web experiment: CYP1A induction and visual tracking of persistent organic pollutants. Environ Toxicol Chem 35(7):1656-1666

7. Beckingham B, Ghosh U (2017) Differential bioavailability of polychlorinated biphenyls associated with environmental particles: microplastic in comparison to wood, coal and biochar. Environ Pollut 220:150-158

8. Bergmann M, Wirzberger V, Krumpen T, Lorenz C, Primpke S, Tekman MB, Gerdts G (2017) High quantities of microplastic in Arctic deep-sea sediments from the HAUSGARTEN observatory. Environ Sci Technol 51(19):11000-11010

9. Bradford MM (1976) A rapid and sensitive method for the quantitation of microgram quantities of protein utilizing the principle of protein-dye binding. Anal Biochem 72(1):248-254

10. Bundschuh M, Goedkoop W, Kreuger J (2014) Evaluation of pesticide monitoring strategies in agricultural streams based on the toxic-unit concept-experiences from long-term measurements. Sci Total Environ 484:84-91

11. Chen Q, Gundlach M, Yang S, Jiang J, Velki M, Yin D, Hollert H (2017) Quantitative investigation of the mechanisms of microplastics and nanoplastics toward zebrafish larvae locomotor activity. Sci Total Environ 584-585:1022-1031

12. de Sá LC, Oliveira M, Ribeiro F, Rocha TL, Futter MN (2018) Studies of the effects of microplastics on aquatic organisms: what do we know and where should we focus our efforts in the future? Sci Total Environ 645:1029-1039

13. Dieterich A, Troschinski S, Schwarz S, Di Lellis MA, Henneberg A, Fischbach U, Ludwig M, Gärtner U, Triebskorn R, Köhler H-R (2015) Hsp70 and lipid peroxide levels following heat stress in Xeropicta derbentina (Krynicki 1836) (Gastropoda, Pulmonata) with regard to different colour morphs. Cell Stress Chaperones 20(1):159-168 
14. Ding J, Zhang S, Razanajatovo RM, Zou H, Zhu W (2018) Accumulation, tissue distribution, and biochemical effects of polystyrene microplastics in the freshwater fish red tilapia (Oreochromis niloticus). Environ Pollut 238:1-9

15. Dris R, Imhof H, Sanchez W, Gasperi J, Galgani F, Tassin B, Laforsch C (2015) Beyond the ocean: contamination of freshwater ecosystems with (micro-) plastic particles. Environ Chem 12(5):539-550

16. EFSA (2006) Conclusion on the peer review of methiocarb. Sci Rep EFSA 79:1-82

17. Eitzen L, Paul S, Braun U, Altmann K, Jekel M, Ruhl AS (2019) The challenge in preparing particle suspensions for aquatic microplastic research. Environ Res 168:490-495

18. Ellman GL, Courtney KD, Andres V, Featherstone RM (1961) A new and rapid colorimetric determination of acetylcholinesterase activity. Biochem Pharmacol 7(2):88-95

19. EPA (2020) Chemistry dashboard: methiocarb. https://comptox.epa.gov/ dashboard/DTXSID3032626. Accessed 26 Feb 2020

20. EPA (1994) R.E.D. facts methiocarb. E. P. Agency. United States

21. Essawy AE, Abdelmeguied NE, Radwan MA, Hamed SS, Hegazy AE (2008) Neuropathological effect of carbamate molluscicides on the land snail, Eobania vermiculata. Cell Biol Toxicol 25(3):275

22. EU (2006) Council directive 2006/88/EC. Off J Eur Union L 328:14-56

23. European Commission (2014) Commission implementing regulation (EU) No 187/2014 amending implementing regulation (EU) No 540/2011 as regards the conditions of approval of the active substance methiocarb. Off J Eur Union L 57:24-26

24. European Commission (2015) Development of the first watch list under the environmental quality standards directive. European Commission, Brussels

25. European Commission (2019) Commission implementing regulation (EU) 2019/707. Off J Eur Union L 120:16-19

26. European Commission (2019) Commission implementing regulation (EU) 2019/1606. Off J Eur Union L 250:53-55

27. Ferreira P, Fonte E, Soares ME, Carvalho F, Guilhermino L (2016) Effects of multi-stressors on juveniles of the marine fish Pomatoschistus microps: gold nanoparticles, microplastics and temperature. Aquat Toxicol 170:89-103

28. Fonte E, Ferreira P, Guilhermino L (2016) Temperature rise and microplastics interact with the toxicity of the antibiotic cefalexin to juveniles of the common goby (Pomatoschistus microps): post-exposure predatory behaviour, acetylcholinesterase activity and lipid peroxidation. Aquat Toxicol 180:173-185

29. Fukuto TR (1990) Mechanism of action of organophosphorus and carbamate insecticides. Environ Health Perspect 87:245-254

30. Furnes B, Schlenk D (2005) Extrahepatic metabolism of carbamate and organophosphate thiother compounds by the flavin-containing monooxyenase and cytochrome p450 systems. Drug Metab Dispos 33(2):214

31. Guilhermino L, Vieira LR, Ribeiro D, Tavares AS, Cardoso V, Alves A, Almeida JM (2018) Uptake and effects of the antimicrobial florfenicol, microplastics and their mixtures on freshwater exotic invasive bivalve Corbicula fluminea. Sci Total Environ 622-623:1131-1142

32. Hermes-Lima M, Willmore WG, Storey KB (1995) Quantification of lipid peroxidation in tissue extracts based on Fe(III)xylenol orange complex formation. Free Radical Biol Med 19(3):271-280

33. Horton AA, Walton A, Spurgeon DJ, Lahive E, Svendsen C (2017) Microplastics in freshwater and terrestrial environments: evaluating the current understanding to identify the knowledge gaps and future research priorities. Sci Total Environ 586:127-141

34. ILO (2012) International Chemical Safety Cards (ICSC): Methiocarb. ICSC: 1766 http://www.ilo.org/dyn/icsc/showcard.display?p_version=2\&p_ card_id=1766. Accessed 11 Dec 2019

35. Jeong C-B, Won E-J, Kang H-M, Lee M-C, Hwang D-S, Hwang U-K, Zhou B, Souissi S, Lee S-J, Lee J-S (2016) Microplastic size-dependent toxicity, oxidative stress induction, and p-JNK and p-p38 activation in the monogonont rotifer (Brachionus koreanus). Environ Sci Technol 50(16):8849-8857

36. Johnson WW, Finley MT (1980) Handbook of acute toxicity of chemicals to fish and aquatic invertebrates: summaries of toxicity tests conducted at Columbia National Fisheries Research Laboratory, 1965-1978. Resource Publication, Columbia, p 106
37. Karami A, Romano N, Galloway T, Hamzah H (2016) Virgin microplastics cause toxicity and modulate the impacts of phenanthrene on biomarker responses in African catfish (Clarias gariepinus). Environ Res 151:58-70

38. Kleinteich J, Seidensticker S, Marggrander N, Zarfl C (2018) Microplastics reduce short-term effects of environmental contaminants. Part II: polyethylene particles decrease the effect of polycyclic aromatic hydrocarbons on microorganisms. Int J Environ Res Public Health 15(2):287

39. Köck-Schulmeyer M, Ginebreda A, Postigo C, Garrido T, Fraile J, López de Alda M, Barceló D (2014) Four-year advanced monitoring program of polar pesticides in groundwater of Catalonia (NE-Spain). Sci Total Environ 470-471:1087-1098

40. Koelmans AA, Bakir A, Burton GA, Janssen CR (2016) Microplastic as a vector for chemicals in the aquatic environment: critical review and modelsupported reinterpretation of empirical studies. Environ Sci Technol 50(7):3315-3326

41. Lei L, Wu S, Lu S, Liu M, Song Y, Fu Z, Shi H, Raley-Susman KM, He D (2018) Microplastic particles cause intestinal damage and other adverse effects in zebrafish Danio rerio and nematode Caenorhabditis elegans. Sci Total Environ 619-620:1-8

42. Lithner D, Damberg J, Dave G, Larsson $\AA$ (2009) Leachates from plastic consumer products - screening for toxicity with Daphnia magna. Chemosphere 74(9):1195-1200

43. Loos R, Marinov D, Sanseverino I, Napierska D, Lettieri T (2018) Review of the 1st watch list under the water framework directive and recommendations for the 2nd Watch List. Publications Office of the European Union, Luxembourg

44. Lu Y, Zhang Y, Deng Y, Jiang W, Zhao Y, Geng J, Ding L, Ren H (2016) Uptake and accumulation of polystyrene microplastics in zebrafish (Danio rerio) and toxic effects in liver. Environ Sci Technol 50(7):4054-4060

45. Luís LG, Ferreira P, Fonte E, Oliveira M, Guilhermino L (2015) Does the presence of microplastics influence the acute toxicity of chromium(VI) to early juveniles of the common goby (Pomatoschistus microps)? A study with juveniles from two wild estuarine populations. Aquat Toxicol 164:163-174

46. Lushchak VI (2016) Contaminant-induced oxidative stress in fish: a mechanistic approach. Fish Physiol Biochem 42(2):711-747

47. Magni S, Gagné F, André C, Della Torre C, Auclair J, Hanana H, Parenti CC, Bonasoro F, Binelli A (2018) Evaluation of uptake and chronic toxicity of virgin polystyrene microbeads in freshwater zebra mussel Dreissena polymorpha (Mollusca: Bivalvia). Sci Total Environ 631-632:778-788

48. Markwell MAK, Haas SM, Bieber LL, Tolbert NE (1978) A modification of the Lowry procedure to simplify protein determination in membrane and lipoprotein samples. Anal Biochem 87(1):206-210

49. Mattsson K, Johnson EV, Malmendal A, Linse S, Hansson L-A, Cedervall T (2017) Brain damage and behavioural disorders in fish induced by plastic nanoparticles delivered through the food chain. Sci Rep 7(1):11452

50. Maymó AC, Cervera A, Dolores Garcerá M, Bielza P, Martínez-Pardo $\mathrm{R}$ (2006) Relationship between esterase activity and acrinathrin and methiocarb resistance in field populations of western flower thrips, Frankliniella occidentalis. Pest Manag Sci 62(12):1129-1137

51. Moermond CTA, Kase R, Korkaric M, Ågerstrand M (2016) CRED: criteria for reporting and evaluating ecotoxicity data. Environ Toxicol Chem 35(5):1297-1309

52. Monserrat JM, Geracitano LA, Pinho GLL, Vinagre TM, Faleiros M, Alciati JC, Bianchini A (2003) Determination of lipid peroxides in invertebrates tissues using the Fe(III) xylenol orange complex formation. Arch Environ Contam Toxicol 45(2):177-183

53. Nematdoost Haghi B, Banaee M (2017) Effects of micro-plastic particles on paraquat toxicity to common carp (Cyprinus carpio): biochemical changes. Int J Environ Sci Technol 14(3):521-530

54. Oliveira M, Ribeiro A, Hylland K, Guilhermino L (2013) Single and combined effects of microplastics and pyrene on juveniles ( $0+$ group) of the common goby Pomatoschistus microps (Teleostei, Gobiidae). Ecol Ind 34:641-647

55. Ozden S, Alpertunga B (2010) Effects of methiocarb on lipid peroxidation and glutathione level in rat tissues. Drug Chem Toxicol 33(1):50-54

56. Ozden S, Catalgol B, Gezginci-Oktayoglu S, Karatug A, Bolkent S, Alpertunga B (2012) Acute effects of methiocarb on oxidative damage and the protective effects of vitamin $\mathrm{E}$ and taurine in the liver and kidney of Wistar rats. Toxicol Ind Health 29(1):60-71 
57. Paul-Pont I, Lacroix C, González Fernández C, Hégaret H, Lambert C, Le Goïc N, Frère L, Cassone A-L, Sussarellu R, Fabioux C, Guyomarch J, Albentosa M, Huvet A, Soudant P (2016) Exposure of marine mussels Mytilus spp. to polystyrene microplastics: toxicity and influence on fluoranthene bioaccumulation. Environ Pollut 216:724-737

58. Pesticide Action Network (2000-2019) PAN Pesticide Database. http:// www.pesticideinfo.org. Accessed 1 Sept 2019

59. Qiao R, Sheng C, Lu Y, Zhang Y, Ren H, Lemos B (2019) Microplastics induce intestinal inflammation, oxidative stress, and disorders of metabolome and microbiome in zebrafish. Sci Total Environ 662:246-253

60. Rainieri S, Conlledo N, Larsen BK, Granby K, Barranco A (2018) Combined effects of microplastics and chemical contaminants on the organ toxicity of zebrafish (Danio rerio). Environ Res 162:135-143

61. Rault M, Collange B, Mazzia C, Capowiez Y (2008) Dynamics of acetylcholinesterase activity recovery in two earthworm species following exposure to ethyl-parathion. Soil Biol Biochem 40(12):3086-3091

62. Rehse S, Kloas W, Zarfl C (2018) Microplastics reduce short-term effects of environmental contaminants. Part I: effects of bisphenol A on freshwater zooplankton are lower in presence of polyamide particles. Int J Environ Res Public Health 15(2):280

63. Rochman CM, Hoh E, Kurobe T, Teh SJ (2013) Ingested plastic transfers hazardous chemicals to fish and induces hepatic stress. Sci Rep 3:3263

64. Rochman CM, Kurobe T, Flores I, Teh SJ (2014) Early warning signs of endocrine disruption in adult fish from the ingestion of polyethylene with and without sorbed chemical pollutants from the marine environment. Sci Total Environ 493:656-661

65. Romano N, Ashikin M, Teh JC, Syukri F, Karami A (2018) Effects of pristine polyvinyl chloride fragments on whole body histology and protease activity in silver barb Barbodes gonionotus fry. Environ Pollut 237:1106-1111

66. Rosman Y, Makarovsky I, Bentur Y, Shrot S, Dushnistky T, Krivoy A (2009) Carbamate poisoning: treatment recommendations in the setting of a mass casualties event. Am J Emerg Med 27(9):1117-1124

67. Sanchez-Hernandez JC, Mazzia C, Capowiez Y, Rault M (2009) Carboxylesterase activity in earthworm gut contents: potential (eco)toxicological implications. Comp Biochem Physiol C: Toxicol Pharmacol 150(4):503-511

68. Schiavo S, Oliviero M, Romano V, Manzo S (2018) Ecotoxicological assessment of virgin plastic pellet leachates in freshwater matrices. J Environ Account Manag 6(4):345-353

69. Schmidt-Posthaus H, Bernet D, Wahli T, Burkhardt-Holm P (2001) Morphological organ alterations and infectious diseases in brown trout Salmo trutta and rainbow trout Oncorhynchus mykiss exposed to polluted river water. Dis Aquat Organ 44(3):161-170

70. Sleight VA, Bakir A, Thompson RC, Henry TB (2017) Assessment of microplastic-sorbed contaminant bioavailability through analysis of biomarker gene expression in larval zebrafish. Mar Pollut Bull 116(1):291-297

71. Smith R, Middlebrook R, Turner R, Huggins R, Vardy S, Warne M (2012) Large-scale pesticide monitoring across great barrier reef catchments - paddock to reef integrated monitoring, modelling and reporting program. Mar Pollut Bull 65(4):117-127

72. Su L, Cai H, Kolandhasamy P, Wu C, Rochman CM, Shi H (2018) Using the Asian clam as an indicator of microplastic pollution in freshwater ecosystems. Environ Pollut 234:347-355

73. Tourinho PS, Kočí V, Loureiro S, van Gestel CAM (2019) Partitioning of chemical contaminants to microplastics: sorption mechanisms, environmental distribution and effects on toxicity and bioaccumulation. Environ Pollut 252:1246-1256

74. Triebskorn R, Braunbeck T, Grummt T, Hanslik L, Huppertsberg S, Jekel M, Knepper TP, Krais S, Müller YK, Pittroff M, Ruhl AS, Schmieg H, Schür C, Strobel C, Wagner M, Zumbülte N, Köhler H-R (2019) Relevance of nano- and microplastics for freshwater ecosystems: a critical review. TrAC 110:375-392

75. Triebskorn R, Telcean I, Casper H, Farkas A, Sandu C, Stan G, Colărescu O, Dori T, Köhler H-R (2008) Monitoring pollution in River Mureş, Romania, part II: metal accumulation and histopathology in fish. Environ Monit Assess 141(1):177-188

76. Usmani KA, Karoly ED, Hodgson E, Rose RL (2004) In vitro sulfoxidation of thioether compounds by human cytochrome p459 and flavin-containing monooxygenase isoforms with particular preference to the CYP2C subfamily. Drug Metab Dispos 32(3):333

77. van Pomeren M, Brun NR, Peijnenburg WJGM, Vijver MG (2017) Exploring uptake and biodistribution of polystyrene (nano)particles in zebrafish embryos at different developmental stages. Aquat Toxicol 190:40-45

78. von Moos N, Burkhardt-Holm P, Köhler A (2012) Uptake and effects of microplastics on cells and tissue of the blue mussel Mytilus edulis L. after an experimental exposure. Environ Sci Technol 46(20):11327-11335

79. Wang F, Wong CS, Chen D, Lu X, Wang F, Zeng EY (2018) Interaction of toxic chemicals with microplastics: a critical review. Water Res 139:208-219

80. Wen B, Zhang N, Jin S-R, Chen Z-Z, Gao J-Z, Liu Y, Liu H-P, Xu Z (2018) Microplastics have a more profound impact than elevated temperatures on the predatory performance, digestion and energy metabolism of an Amazonian cichlid. Aquat Toxicol 195:67-76

81. Wheelock CE, Shan G, Ottea J (2005) Overview of carboxylesterases and their role in the metabolism of insecticides. J Pest Sci 30(2):75-83

82. Worthing CR, Hance RJ, Council British Crop Protection (1991) The pesticide manual a world compendium Surrey. UK British Crop Protection Council, Farnham

\section{Publisher's Note}

Springer Nature remains neutral with regard to jurisdictional claims in published maps and institutional affiliations.

\section{Submit your manuscript to a SpringerOpen ${ }^{\circ}$ journal and benefit from:}

- Convenient online submission

- Rigorous peer review

- Open access: articles freely available online

- High visibility within the field

Retaining the copyright to your article

Submit your next manuscript at springeropen.com 